\title{
Lysophosphatidic acid-induced oxidized low-density lipoprotein uptake is class A scavenger receptor-dependent in macrophages
}

\author{
Chi-Lun Chang ${ }^{\mathrm{a}}$, Hsien-Yeh Hsu ${ }^{\mathrm{e}}$, Hong-Yu Lin ${ }^{\mathrm{c}}$, Wenchang Chiang c, d ${ }^{\mathrm{d}}$, Hsinyu Lee ${ }^{\mathrm{a}, \mathrm{b}, *}$ \\ a Institute of Zoology, National Taiwan University, Taipei, Taiwan, ROC \\ ' Department of Life Science, National Taiwan University, Taipei, Taiwan, ROC \\ c Institute of Food Science and Technology, National Taiwan University, Taipei, Taiwan, ROC \\ d Center for Food and Biomolecules, National Taiwan University, Taipei, Taiwan, ROC \\ e Institute of Biotechnology in Medicine, National Yang-Ming University, Taipei, Taiwan, ROC
}

\section{A R T I C L E I N F O}

\section{Article history:}

Received 21 April 2008

Accepted 30 May 2008

Available online 8 June 2008

\section{Keywords:}

LPA

Scavenger receptor

OxLDL uptake

Macrophages

\begin{abstract}
A B S T R A C T
Lysophosphatidic acid (LPA) is a low-molecular-weight lysophospholipid enriched in platelets and mildly oxidized low-density lipoprotein (OxLDL). It is suggested that LPA is involved in atherosclerosis, and our previous studies showed that LPA regulates inflammation in multiple cell types. The main aim of this study was to investigate the effects of LPA on the uptake of OxLDL by mouse J774A.1 macrophages. We observed that LPA upregulated fluorescence-labeled DiI-OxLDL uptake in J774A.1 cells. Meanwhile, expression of the class A scavenger receptor (SR-A), a receptor for modified LDL, was also enhanced. Furthermore, pertussis toxin (PTx) or Ki16425 significantly abolished LPA's effects, indicating that $G_{i}$ and $\mathrm{LPA}_{3}$ are involved in OxLDL uptake and SR-A expression. Of most importance, the LPA-induced OxLDL uptake could be inhibited when cells were incubated with a functional blocking antibody of SR-A. Our results suggest that $L P A-e n h a n c e d ~ O x L D L$ uptake is mediated via $L^{2} A_{3}-G_{i}$ activation and subsequent SR-A expression.
\end{abstract}

(C) 2008 Elsevier Inc. All rights reserved.

\section{Introduction}

Lysophosphatidic acid (LPA) is a simple lysophospholipid with a variety of biological activities. LPA mainly comes from platelets and mildly oxidized low-density lipoprotein (OxLDL), while LPA is also present in serum, saliva, follicular fluid, and malignant effusions [1-4]. The biological effects elicited by LPA are mediated through recognition of LPA by a series of G-protein-coupled receptors (GPCRs), $\mathrm{LPA}_{1}, \mathrm{LPA}_{2}$, and $\mathrm{LPA}_{3}$, encoded by endothelial differentiating genes $(E d g)[5,6]$. In addition, LPA is known to bind and activate the transcription factor, peroxisome proliferator-activated receptor $\gamma$ (PPAR $\gamma$ ), indicating that PPAR $\gamma$ is an intracellular receptor for LPA [7].

LPA regulates inflammation in multiple cell types. In human endothelial cells, it induces wound healing, cell proliferation, and the expressions of ICAM-1, IL-8, MCP-1, and MMP-2 [8-11]. On the other hand, LPA induces calcium mobilization and the release of reactive oxygen species (ROS) in human monocytic cells [12,13]. In

\footnotetext{
* Corresponding author at: Department of Life Science and Institute of Zoology, National Taiwan University, 1 Roosevelt Road, Section 4, Taipei 106, Taiwan. Tel.: +8862 3366 2499; fax: +886223636837.

E-mail address: hsinyu@ntu.edu.tw (H. Lee).
}

mouse J774A.1 macrophages, LPA also enhances IL-1 $\beta$ expression through the production of ROS [14].

Atherosclerosis is an inflammatory disease [15]. Macrophages play multiple roles in the process of atherosclerosis. One wellknown hallmark is the uptake of modified LDL, such as OxLDL, by macrophages, leading to the formation of foam cells [16]. Furthermore, scavenger receptors are responsible for the uptake of modified LDL by macrophages. The class A scavenger receptor (SRA) is expressed on the surface of macrophages, aortic endothelial cells, and smooth muscle cells in atherosclerotic lesions [17,18]. Studies of SR-A null mice suggested that lipid uptake via the SRA is atherogenic [19]. On the other hand, LPA is an important regulator of atherogenesis by induction of neointima formation through PPAR $\gamma$ activation in a rat carotid artery model [20]. In addition, it is suggested that bioactive LPA is synthesized during LDL oxidation and accumulates in atherosclerotic lesions, which provides further evidence for the involvement of LPA in atherosclerosis [3].

It is currently unclear about the relationships between the atherogenic effects of LPA and macrophages. In this study, we attempted to determine whether LPA plays a role in OxLDL uptake in macrophages. Our data showed that LPA enhances OxLDL uptake in mouse J774A.1 cells. Furthermore, by using chemical inhibitors and an SR-A functional blocking antibody, we demonstrated that 
$\mathrm{LPA}_{3}-\mathrm{G}_{\mathrm{i}}$ activation and downstream SR-A expression are important in OxLDL uptake enhanced by LPA in J774A.1 cells.

\section{Materials and methods}

\subsection{Reagents}

1-Oleoyl-lysophosphatidic acid (LPA), pertussis toxin (PTx), fatty acid-free bovine serum albumin (faf-BSA), and Ki16425 were purchased from Sigma (St. Louis, MO). The monoclonal rat antimouse scavenger receptor class A (SR-A) antibody (MCA1322EL) was from AbD Serotec (Oxford, UK). TRIzol, RPMI 1640 medium, rhodamine-conjugated goat anti-rat immunoglobulin $\mathrm{G}(\operatorname{IgG}), 1,1^{\prime}$ dioctadecyl-3,3,3',3'-tetramethylindocarbocyanine (DiI), and the Superscript II kit were purchased from Invitrogen (Grand Island, NY). Fetal bovine serum (FBS) was from HyClone (South Logan, UT).

\subsection{Cell lines and culture}

The murine J774A.1 macrophage cell line was obtained from the American Type Culture Collection (ATCC; Manassas, VA). Cells were cultured in RPMI 1640 medium supplemented with $10 \%$ heatinactivated $\mathrm{FBS}$ at $37^{\circ} \mathrm{C}$ under a humidified atmosphere of $5 \% \mathrm{CO}_{2}$. Experiments were performed with cells which had gone through no more then 10 passages since receipt.

\subsection{DiI-OxLDL uptake assay}

LDL isolation, and Dil labeling and oxidation were carried out as described previously [21]. Starved cells were treated with the indicated concentrations of LPA for $16 \mathrm{~h}$. Then $50 \mu \mathrm{g} / \mathrm{ml}$ Dil-OxLDL was added to the treatments for another $5 \mathrm{~h}$ in darkness [22]. After treatment, cells were washed with PBS, and the fluorescence intensities of DiI, indicating the capability for OxLDL uptake, in different treatments were determined using a CyFlow flow cytometer from Partec (Münster, Germany). For quantification, the means of the histograms were calculated using the Flowmax program from Partec.

\subsection{Determination of cell-surface SR-A expression levels}

Treated J774A.1 cells were scraped and suspended in $50 \mu$ PBS with $0.1 \%$ BSA containing $10 \mu \mathrm{g} / \mathrm{ml}$ of the monoclonal rat antimouse SR-A antibody on ice for $1 \mathrm{~h}$. Then rhodamine-conjugated goat anti-rat IgG was added to the suspensions at a 1:200 dilution for $30 \mathrm{~min}$. Antibody-labeled cells were subjected to flow cytomet-

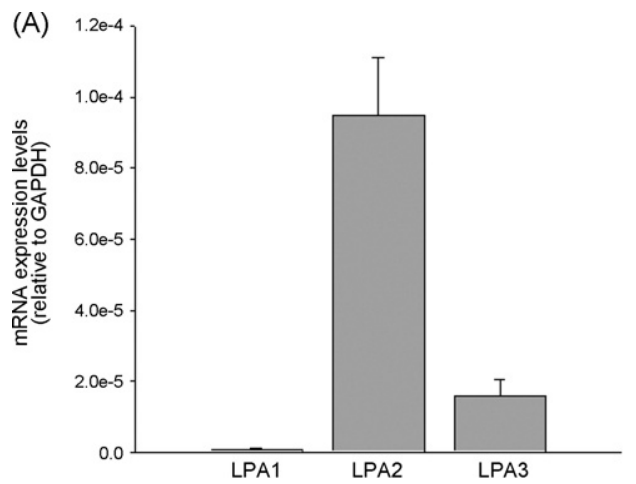

ric analysis using the CyFlow flow cytometer. For quantification, the means of the histograms were calculated using the Flowmax program from Partec.

\subsection{RNA isolation, reverse transcription (RT), and real-time PCR}

Total cellular RNA was extracted from cells using the TRIzol reagent. Total RNA $(1 \mu \mathrm{g})$ was subjected to an RT reaction with an oligo-dT primer using a Superscript II kit. Real-time PCR was carried out using an iCycler iQ real-time detection system with iQ SYBR Green Supermix from Bio-Rad (Hercules, CA). Gene-specific primers were forward: AAGGCTGTGGGCAAGGTCATC, and reverse: CAGGCGGCACGTCAGATCC for GAPDH; forward: CCAGGAGGAATCGGGACAC, and reverse: CAATAACAAGACCAATCCCGGA for $\mathrm{LPA}_{1}$; forward: CCTAGTCAAGACGGTTGTCATCAT, and reverse: ACAGTCCAGGCCATCCAGG for $\mathrm{LPA}_{2}$; forward: TGCTCGCACTGCTCAACTCC, and reverse: GCCTCTCGGTATTGCTGTCCTG for $\mathrm{LPA}_{3}$; forward: AGAGGGCTTACTGGACAAACTG, and reverse: GGCTTTCCTGGTGCTCCTG for SR-A; forward: GAACAGAGCGGAGCAATG, and reverse: GCAGTTGGCAGATGATGG for SR-BI; and forward: AGGTCTATCTACGCTGTGTTC, and reverse: ATGGTTGTCTGGATTCTGGAG for CD36. The specificity was confirmed by melting-curve detection. Cycling conditions were $95^{\circ} \mathrm{C}$ for $3 \mathrm{~min}$, followed by 40 cycles of $95^{\circ} \mathrm{C}$ for $30 \mathrm{~s}, 60^{\circ} \mathrm{C}$ for $30 \mathrm{~s}$, and $72^{\circ} \mathrm{C}$ for $30 \mathrm{~s}$. For quantification, the target gene was normalized to the internal standard gene, GAPDH. Primers for real-time PCR were designed using Beacon Designer 4 software from PREMIER Biosoft International (Palo Alto, CA).

\subsection{Statistical analysis}

Each result was obtained from three independent experiments. Data were statistically analyzed using one-way ANOVA, followed by Fisher's protected least-significant difference test, and a value of $p<0.05$ was considered statistically significant.

\section{Results}

\subsection{LPA receptor and scavenger receptor expression profiles in J774A.1 cells}

We first examined the LPA receptor and scavenger receptor expression profiles in these cells. With the use of specific primers, the results of real-time PCR analysis are shown in Fig. 1. The relative abundance of LPA receptor mRNA in J774A.1 is $\mathrm{LPA}_{2}>\mathrm{LPA}_{3} \gg \mathrm{LPA}_{1}$, while scavenger receptor is $\mathrm{SR}-\mathrm{A}>\mathrm{SR}-\mathrm{BI}>\mathrm{CD} 36$.

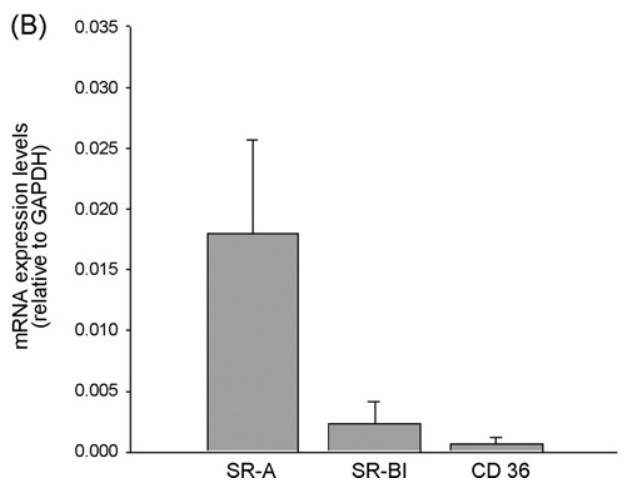

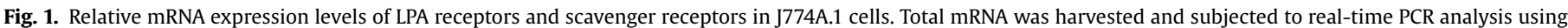
specific primer sets for mouse LPA receptors (A) and scavenger receptors (B). Quantified results are from three independent experiments and shown as the mean \pm S.D. 

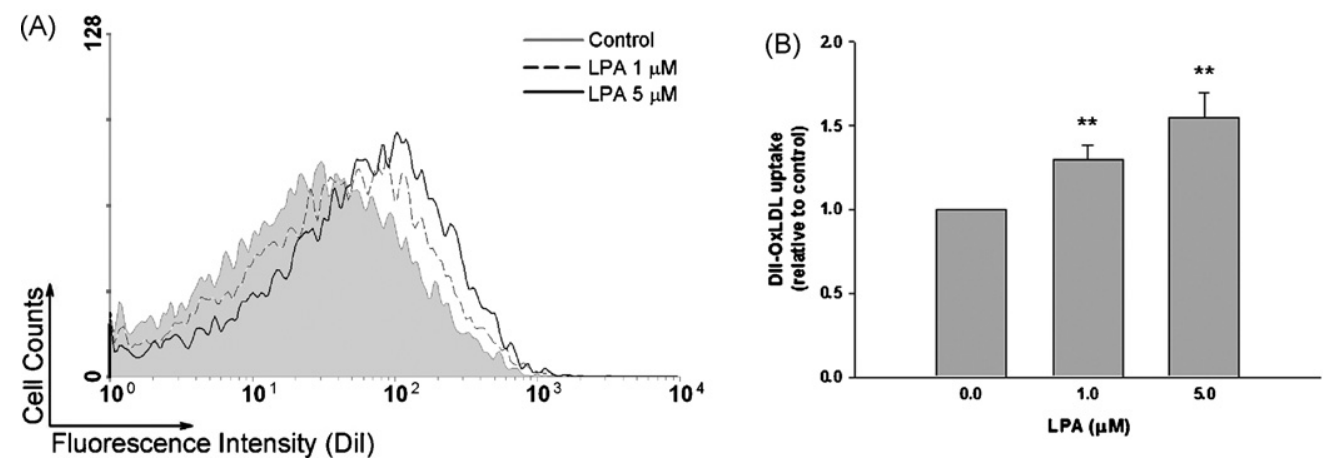

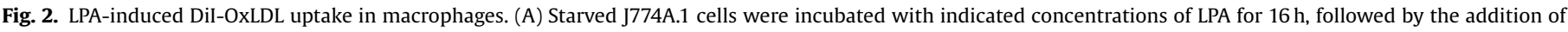

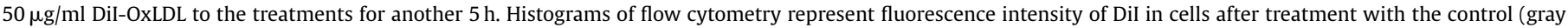
shadow), $1 \mu \mathrm{M}$ LPA (dashed line), or $5 \mu \mathrm{M}$ LPA (black line). (B) Quantified results are from three independent experiments and shown as the mean \pm S.D. ${ }^{* *} p<0.01$.

\subsection{LPA-induced OxLDL uptake in macrophages}

We next assessed whether LPA regulates OxLDL uptake in macrophages. By the flow cytometric analysis, we found that the Dil fluorescence intensity, as an indicator of Dil-OxLDL uptake by cells, was induced by LPA in a concentration-dependent manner in J774A.1 cells (Fig. 2A). LPA at $1 \mu \mathrm{M}$ slightly increased the uptake of OxLDL, while $5 \mu \mathrm{M}$ LPA substantially increased it. Quantified results showed that the ability of J774A.1 cells to uptake DiI-OxLDL was increased by $30 \%$ and $61 \%$ when cells were treated with $1 \mu \mathrm{M} \mathrm{LPA}$ and $5 \mu \mathrm{M}$ LPA, respectively (Fig. 2B).

\section{3. $L P A_{3}-$ and $G_{i}$-dependent pathways are involved in $O x L D L$ uptake induced by LPA}

The effects of LPA are mainly mediated through GPCRs [5,23]. To further confirm whether LPA-induced OxLDL uptake is receptormediated, pharmacological inhibitors specific for certain LPA receptor-dependent pathways were used. As shown in Fig. 3, we found that the stimulatory effect of LPA was significantly attenuated in the presence of $10 \mu \mathrm{M}$ Ki16425 (Fig. 3A) and $15 \mathrm{ng} / \mathrm{ml} \mathrm{PTx}$ (Fig. 3B) $[14,24]$, which are known to respectively block $\mathrm{LPA}_{1} / \mathrm{LPA}_{3}-$ and $\mathrm{G}_{\mathrm{i}}$-dependent signals. J774A.1 cells express relative low level
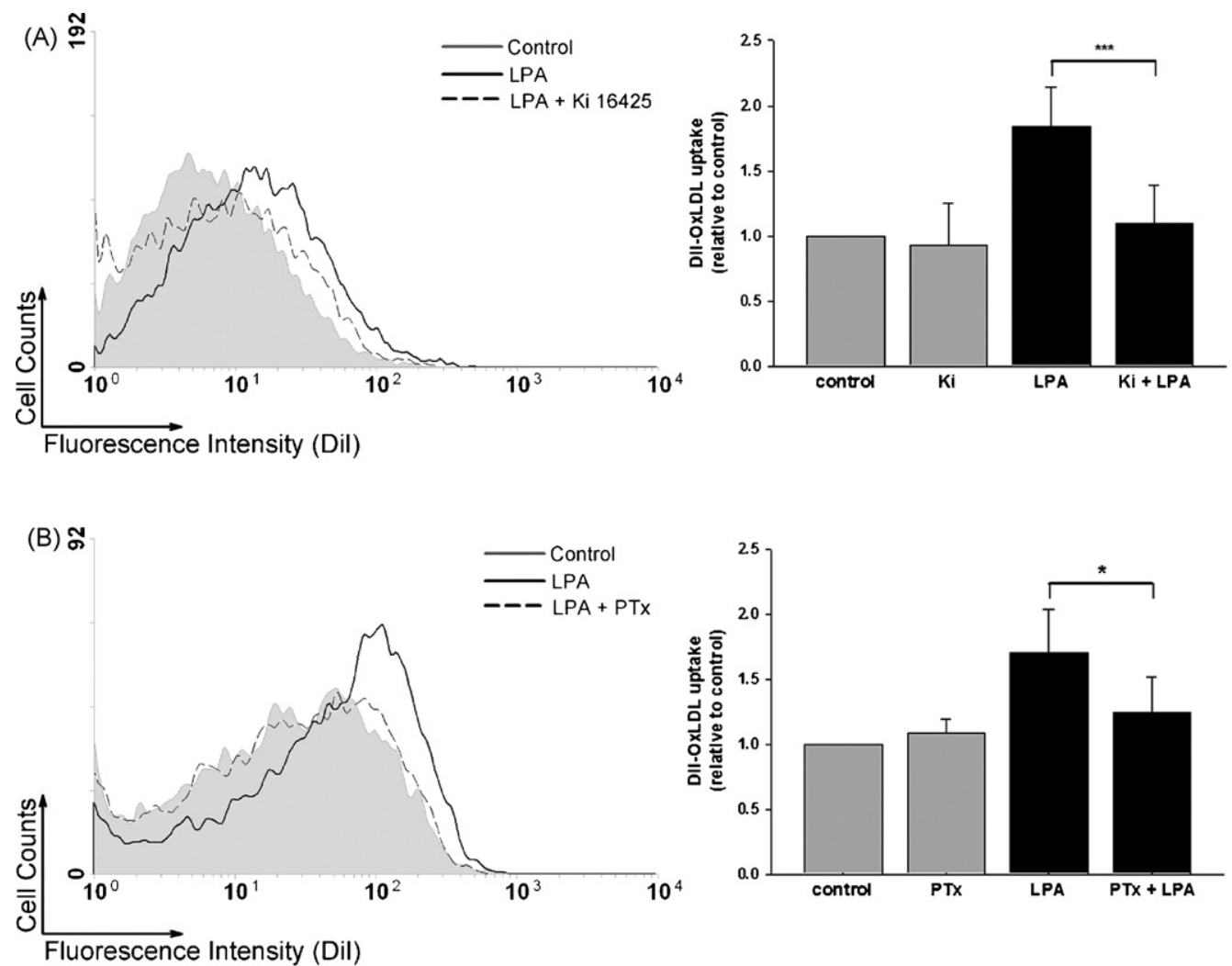

Fluorescence Intensity (Dil)

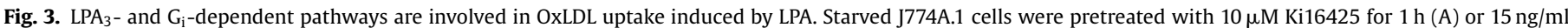

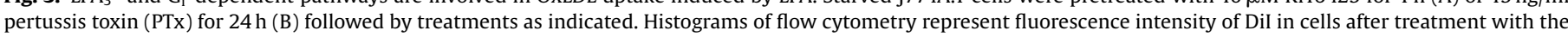

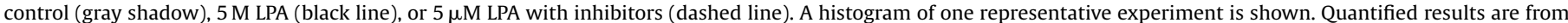
three independent experiments and shown as the mean \pm S.D. ${ }^{*} p<0.05,{ }^{* * *} p<0.001$. 

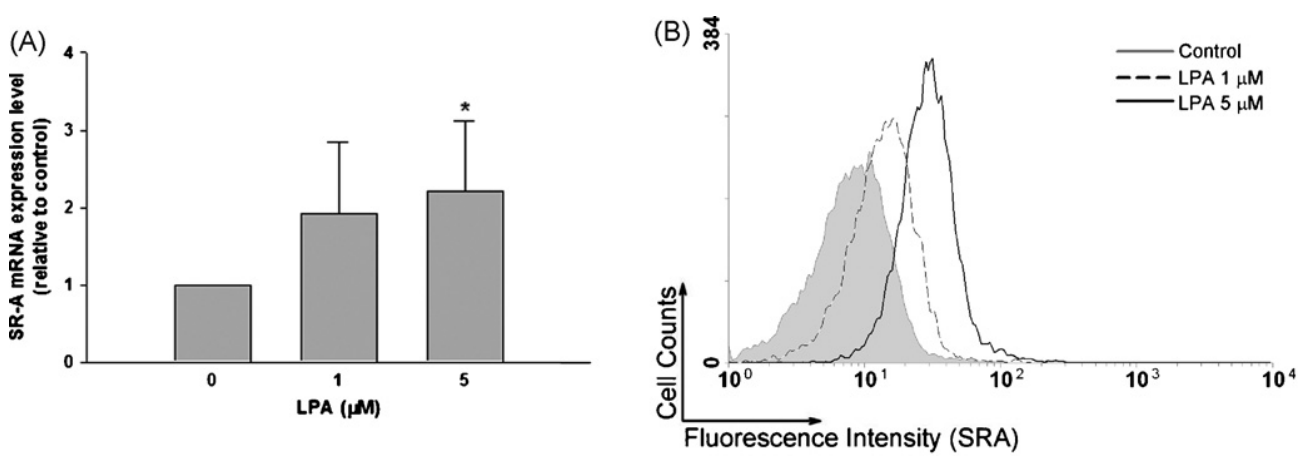

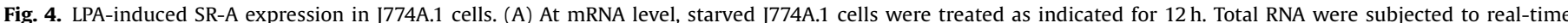

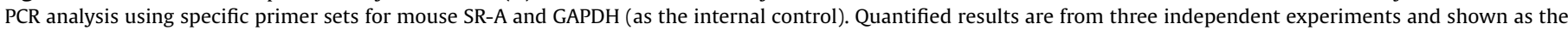

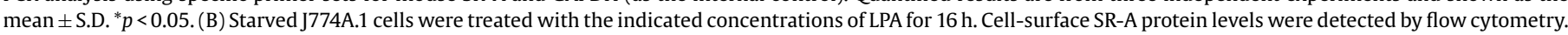
The histogram represents SR-A protein levels in cells after treatment with the control (gray shadow), $1 \mu \mathrm{M}$ LPA (dashed line), or $5 \mu \mathrm{M}$ LPA (black line).

of $\mathrm{LPA}_{1}$ than $\mathrm{LPA}_{3}$ (Fig. 2A), which indicated that the effects of LPA might be mainly through $\mathrm{LPA}_{3}$ activation. Study of Zhang et al. suggested that LPA induced-neointima formation could be inhibited by the PPAR $\gamma$ antagonist, GW9662 [20]. However, pretreatment of GW9662 could not abolish LPA-induced OxLDL uptake in J774A.1 cells, which indicated the absence of PPAR $\gamma$ activation (data not shown).

\subsection{LPA-induced class A scavenger receptor (SR-A) expression is} mediated through $G_{i}$ - and $L P A_{3}$-dependent pathways in J774A.1 cells

Scavenger receptors are responsible for the uptake of modified LDL in macrophages. Previous studies suggested that SR-A, SR-BI, and CD36 affect the development of atherosclerosis lesions [25]. However, GW9662 failed to attenuate LPA-induced OxLDL uptake and LPA treatment did not induce CD36 expression in our model (data not shown), which indicated that CD36 might not be involved in this process. Meanwhile, the basal mRNA level of SR-A was significantly higher than the levels of SR-BI and CD36 in J774A.1 cells (Fig. 2B). Thus, we next determined the effects of LPA on SR-A expression. At the mRNA level, LPA upregulated SR-A expression in a concentration-dependent pattern. The results quantified by the real-time PCR analysis showed that SR-A mRNA was elevated by $1 \mu \mathrm{M} \mathrm{LPA}$, and the expression level peaked with $5 \mu \mathrm{M} \mathrm{LPA}$ treatment for $12 \mathrm{~h}$ (Fig. 4A). Cell surface SR-A protein levels were detected by flow cytometry after LPA treatment for $16 \mathrm{~h}$, and similar results were observed (Fig. 4B). On other hand, Ki16425 (Fig. 5A)
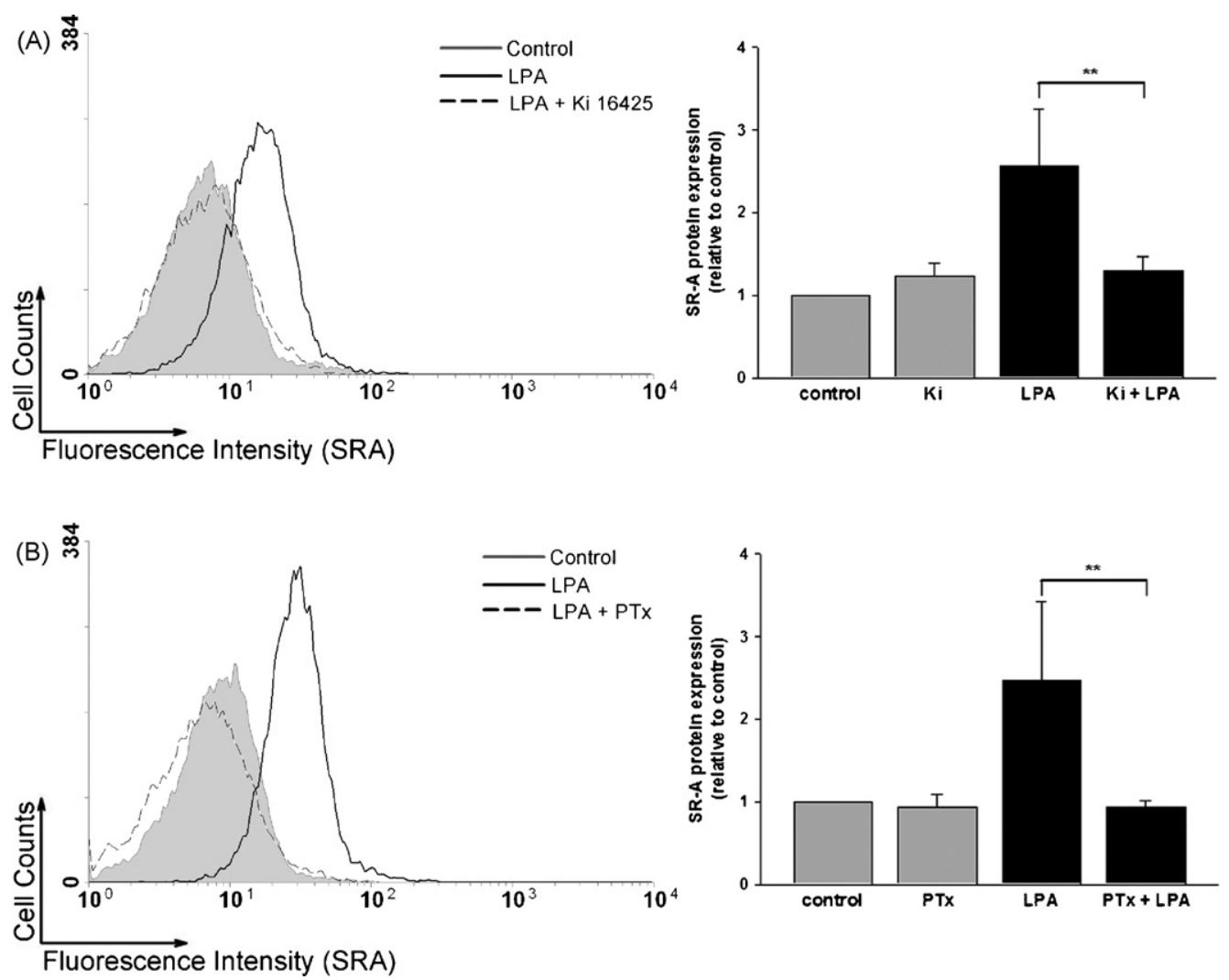

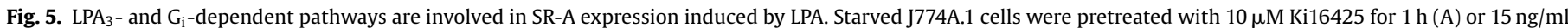

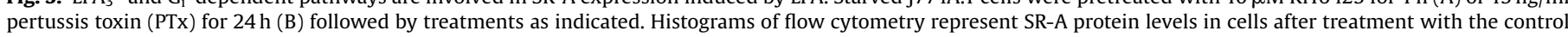

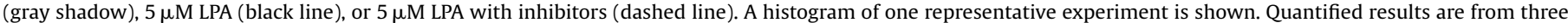
independent experiments and shown as the mean \pm S.D. ${ }^{* *} p<0.01$. 

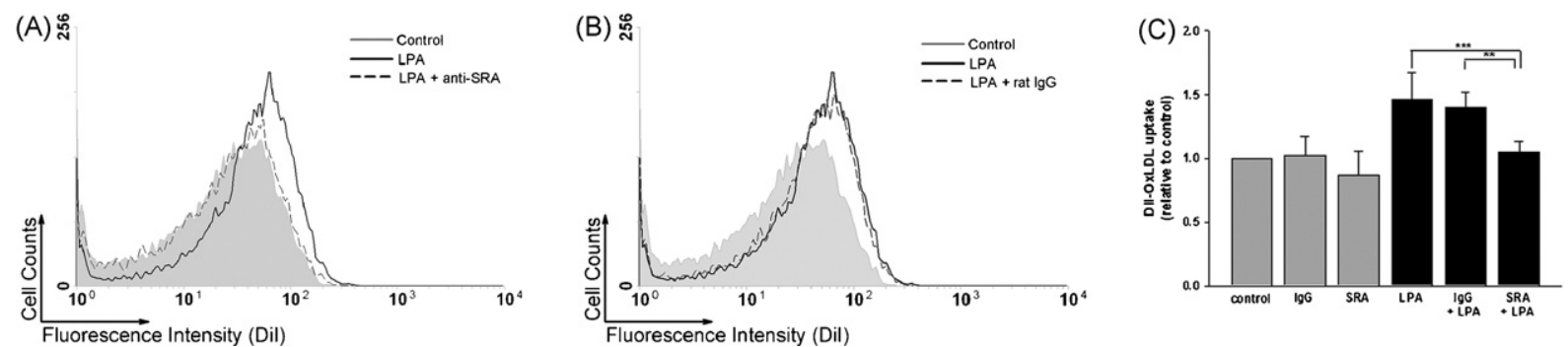

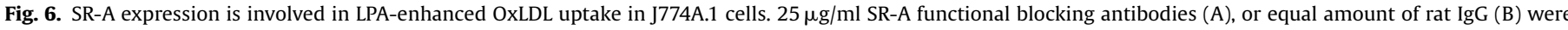

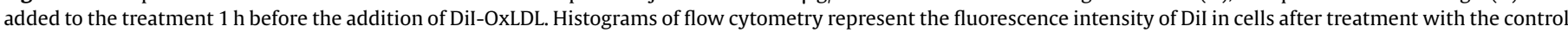

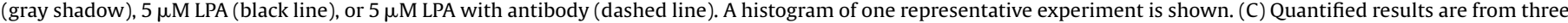
independent experiments and shown as the mean \pm S.D. ${ }^{* *} p<0.01,{ }^{* * *} p<0.001$.

and PTx (Fig. 5B) significantly inhibited SR-A expression enhanced by LPA. These observations indicate that LPA-induced SR-A expression is mediated through $\mathrm{LPA}_{3}$ and $\mathrm{G}_{\mathrm{i}}$ activation.

\subsection{SR-A expression is involved in LPA-enhanced OxLDL uptake in J774A.1 cells}

To further assess the relationship between SR-A expression and OxLDL uptake regulated by LPA, an experiment with an SRA functional blocking antibody was conducted. In the presence of $25 \mu \mathrm{g} / \mathrm{ml}$ of the SR-A antibody, LPA-induced OxLDL uptake was entirely suppressed (Fig. 6A), while the control antibody (rat IgG) had no effects on OxLDL uptake (Fig. 6B). In conclusion, our observations demonstrate that OxLDL uptake in J774A.1 cells is mediated through binding to SR-A, and the enhanced level of OxLDL uptake is correlated to the elevated SR-A expression by LPA.

\section{Discussion}

In the present study, we demonstrated the effects of LPA on OxLDL uptake and SR-A expression in macrophages for the first time. By using chemical inhibitors and an SR-A functional blocking antibody, we showed that SR-A expression downstream of $\mathrm{LPA}_{3}-$ $G_{i}$ activation is required for the process of LPA-induced OxLDL uptake. Previous studies indicated that LPA containing unsaturated rather than saturated fatty acyl groups induced neointima formation $[20,26]$, and $\mathrm{LPA}_{3}$ is preferentially activated by these LPA species [27]. Thus, our results demonstrated that activation of $\mathrm{LPA}_{3}$ is required for the process of foam cell formation enhanced by 1-Oleoyl-LPA in mouse macrophages is physiological relevant. In contrast to our observation, work of Zhang et al. demonstrated that LPA-induced neointima formation could be completely abolished by PPAR $\gamma$ antagonist in rat carotid artery [20]. However, their results also showed that PTx partially attenuated neointima formation, which is consistent to our observations. In addition, Yoshida et al. observed that vascular smooth muscle cells (VSMCs) dedifferentiation and subsequently macrophage infiltration both participate in LPA-induced neointima formation [26]. Thus, attenuation of neointima formation by PTx might be due to the inhibition of LPA's effects on foam cell formation in macrophages rather than affecting VSMCs behavior. Our current study and previous reports indicated that LPA might use alternative signaling pathways between VSMCs and macrophages in regulating the process of atherosclerosis [20].

LPA is reported to stimulate OxLDL uptake through CD36 expression in human monocytes with elevated PPAR $\gamma$ expression induced by ICAM-3 ligation and induce CD36 promoter function in mouse RAW264.7 macrophages [7]. In this study, CD36 expression is unaltered upon LPA stimulus (data not shown). Several reports have suggested that macrophages derived from different species might respond inconsistently [28-30], and the change of PPAR $\gamma$ level by ICAM-3 ligation and transfection of CD36 promoter might influence macrophage behavior. In the future, studies on macrophages derived from $\mathrm{LPA}_{1}-\mathrm{LPA}_{3}$, PPAR $\gamma$, SR-A, or CD36 null mice could provide pivotal information in understanding how LPA regulates the process of atherosclerosis.

Macrophages play multiple roles in the process of atherosclerosis [16]. The earliest event is the recruitment of circulating monocytes into the subendothelium, where monocytes differentiate into macrophages. LPA participates in this initial stage by stimulating expressions of the chemoattractant proteins, IL-8 and MCP-1, and the adhesion molecule, ICAM-1, in endothelial cells $[9,10]$. Moreover, LPA is known to activate human monocytes by inducing calcium mobilization, ROS production, and prostaglandin E2 release [12,13]. Next, differentiated macrophages contribute to inflammatory responses in early lesions. Our previous studies suggested that LPA increases the expression of the proinflammatory genes, IL- $1 \beta$ and TNF- $\alpha$, as well as ROS production in mouse macrophages $[14,31]$. Furthermore, OxLDL is the main source of bioactive LPA in atherosclerotic lesions [3], which further intensifies local inflammatory responses. In comparison with these studies, we further confirm that LPA may contribute to atherosclerosis by controlling OxLDL uptake in macrophages.

Diverse cellular functions in macrophages are regulated by OxLDL. In J774A.1 macrophages, ligands of SR-A, including OxLDL and fucoidan, induce the expression of the urokinase-type plasminogen activator (uPA), IL-1 $\beta$, and TNF- $\alpha[32,33]$. In addition, OxLDL treatment enhances mouse peritoneal macrophages proliferation through ERK/p38 MAPK activation [34]. Coincidentally, LPA has similar proinflammatory and survival-promoting effects in macrophages $[14,35]$. These studies indicated that LPA accumulated in OxLDL might be a potential candidate for regulating macrophage behavior. In addition, cooperation of the SR-A and CD36 is required for platelet activation by OxLDL [36]. In atherosclerotic lesions, elevated SR-A expression might assist the delivery of bioactive LPA in OxLDL to the proximity of macrophages. Thus, the SR-A-mediated OxLDL uptake not only results in foam cell formation, but also increases the local concentration of LPA.

It is suggested that $G_{i}$ activation is involved in acetylated LDL (AcLDL) uptake by SR-A in mouse macrophages. However, the expression level of SR-A is unaltered in the presence of pertussis toxin [37]. In contrast, our results demonstrated an alternative in regulating OxLDL uptake through $\mathrm{G}_{\mathrm{i}}$-dependent SR-A expression, and also indicated that distinct modulating mechanisms might be applied to different ligands of the SR-A. Although lipid uptake through the SR-A is generally considered as proatherogenic [19], the role of SR-A in atherosclerosis is still controversial. In patients with acute coronary syndrome (ACS), the SR-A expression level is elevated in peripheral blood mononuclear cells (PBMCs) [38]. In addition, macrophages peripheral to the atherosclerotic core 
exhibit increased levels of SR-A expression, while macrophages in the core lesions are rarely SR-A positive [39]. These results indicated that the SR-A is proatherogenic and might play multiple roles among different stages of atherosclerosis. On the contrary, increased level of SR-A expression was reported in rabbits more resistant to atherosclerosis [40]. Furthermore, reduced level of macrophages/endothelial cell adhesion and decreased atherosclerotic lesion area were observed in $\mathrm{Ldlr}^{-1-}$ mice, which overexpressed the extracellular domain of SR-A [41]. To our knowledge, we demonstrate for the first time that LPA upregulates SR-A expression through $\mathrm{LPA}_{3}$ - and $\mathrm{G}_{\mathrm{i}}$-dependent pathways in mouse macrophages. Moreover, the increased level of SR-A might play an atherogenic role by regulating foam cell formation.

\section{Acknowledgments}

We appreciate Yu-Ting Kuo and Ting-En Su of Institute of Zoology, National Taiwan University for technical assistance. This work was supported by grants (NSC95-2311-B-002-018-MY2; to HL) from the National Science Council, Taiwan.

\section{References}

[1] Eichholtz T, Jalink K, Fahrenfort I, Moolenaar WH. The bioactive phospholipid lysophosphatidic acid is released from activated platelets. Biochem J 1993;291(Pt 3):677-80.

[2] Moolenaar WH, van Meeteren LA, Giepmans BN. The ins and outs of lysophosphatidic acid signaling. Bioessays 2004;26(8):870-81.

[3] Siess W, Zangl KJ, Essler M, et al. Lysophosphatidic acid mediates the rapid activation of platelets and endothelial cells by mildly oxidized low density lipoprotein and accumulates in human atherosclerotic lesions. Proc Natl Acad Sci USA 1999;96(12):6931-6.

[4] Tigyi G, Miledi R. Lysophosphatidates bound to serum albumin activate membrane currents in Xenopus oocytes and neurite retraction in PC12 pheochromocytoma cells. J Biol Chem 1992;267(30):21360-7.

[5] Anliker B, Chun J. Lysophospholipid G protein-coupled receptors. J Biol Chem 2004;279(20):20555-8.

[6] Chun J, Goetzl EJ, Hla T, et al. International Union of Pharmacology. XXXIV. Lysophospholipid receptor nomenclature. Pharmacol Rev 2002;54(2):2659.

[7] McIntyre TM, Pontsler AV, Silva AR, et al. Identification of an intracellular receptor for lysophosphatidic acid (LPA): LPA is a transcellular PPARgamma agonist. Proc Natl Acad Sci USA 2003;100(1):131-6.

[8] Lee H, Goetzl EJ, An S. Lysophosphatidic acid and sphingosine 1-phosphate stimulate endothelial cell wound healing. Am J Physiol Cell Physiol 2000;278(3):C612-8.

[9] Lee H, Lin CI, Liao JJ, et al. Lysophospholipids increase ICAM-1 expression in HUVEC through a Gi- and NF-kappaB-dependent mechanism. Am J Physiol Cell Physiol 2004;287(6):C1657-66.

[10] Lin CI, Chen CN, Chen JH, Lee H. Lysophospholipids increase IL-8 and MCP-1 expressions in human umbilical cord vein endothelial cells through an IL-1dependent mechanism. J Cell Biochem 2006;99(4):1216-32.

[11] Wu WT, Chen CN, Lin CI, Chen JH, Lee H. Lysophospholipids enhance matrix metalloproteinase-2 expression in human endothelial cells. Endocrinology 2005; 146(8):3387-400.

[12] D’Aquilio F, Procaccini M, Izzi V, et al. Activatory Properties of Lysophosphatidic Acid on Human THP-1 Cells. Inflammation 2007;30(5):167-77.

[13] Fueller M, Wang de A, Tigyi G, Siess W. Activation of human monocytic cells by lysophosphatidic acid and sphingosine-1-phosphate. Cell Signal 2003;15(4):367-75.

[14] Chang CL, Lin ME, Hsu HY, et al. Lysophosphatidic acid-induced interleukin1 beta expression is mediated through $\mathrm{G}(\mathrm{i}) / \mathrm{Rho}$ and the generation of reactive oxygen species in macrophages. J Biomed Sci 2008;15(3):357-63.

[15] Ross R. Atherosclerosis-an inflammatory disease. N Engl J Med 1999;340(2): $115-26$.

[16] Linton MF, Fazio S. Macrophages, inflammation, and atherosclerosis. Int J Obes Relat Metab Disord 2003;27(Suppl 3):S35-40.
[17] Daugherty A, Cornicelli JA, Welch K, Sendobry SM, Rateri DL. Scavenger receptors are present on rabbit aortic endothelial cells in vivo. Arterioscler Thromb Vasc Biol 1997;17(11):2369-75.

[18] Naito M, Suzuki H, Mori T, Matsumoto A, Kodama T, Takahashi K. Coexpression of type I and type II human macrophage scavenger receptors in macrophages of various organs and foam cells in atherosclerotic lesions. Am J Pathol 1992;141(3):591-9.

[19] Suzuki H, Kurihara Y, Takeya M, et al. A role for macrophage scavenger receptors in atherosclerosis and susceptibility to infection. Nature 1997;386 (6622):292-6.

[20] Zhang C, Baker DL, Yasuda S, et al. Lysophosphatidic acid induces neointima formation through PPARgamma activation. J Exp Med 2004;199(6):763-74.

[21] Devaraj S, Hugou I, Jialal I. Alpha-tocopherol decreases CD36 expression in human monocyte-derived macrophages. J Lipid Res 2001;42(4):521-7.

[22] Hsu HY, Twu YC. Tumor necrosis factor-alpha-mediated protein kinases in regulation of scavenger receptor and foam cell formation on macrophage. J Biol Chem 2000;275(52):41035-48.

[23] Hla T, Lee MJ, Ancellin N, Paik JH, Kluk MJ. Lysophospholipids-receptor revelations. Science 2001;294(5548):1875-8.

[24] Ohta H, Sato K, Murata N, et al. Ki16425, a subtype-selective antagonist for EDGfamily lysophosphatidic acid receptors. Mol Pharmacol 2003;64(4):994-1005.

[25] Moore KJ, Freeman MW. Scavenger receptors in atherosclerosis: beyond lipid uptake. Arterioscler Thromb Vasc Biol 2006;26(8):1702-11.

[26] Yoshida K, Nishida W, Hayashi K, et al. Vascular remodeling induced by naturally occurring unsaturated lysophosphatidic acid in vivo. Circulation 2003;108(14):1746-52.

[27] Bandoh K, Aoki J, Taira A, Tsujimoto M, Arai H, Inoue K. Lysophosphatidic acid (LPA) receptors of the EDG family are differentially activated by LPA species. Structure-activity relationship of cloned LPA receptors. FEBS Lett 2000;478(1-2):159-65.

[28] Mestas J, Hughes CC. Of mice and not men: differences between mouse and human immunology. J Immunol 2004;172(5):2731-8.

[29] Schneemann M, Schoeden G. Macrophage biology and immunology: man is not a mouse. J Leukoc Biol 2007;81(3):579.

[30] Schneemann M, Schoedon G. Species differences in macrophage NO production are important. Nat Immunol 2002;3(2):102.

[31] Lee H, Liao JJ, Graeler M, Huang MC, Goetzl EJ. Lysophospholipid regulation of mononuclear phagocytes. Biochim Biophys Acta 2002;1582(1-3):175-7.

[32] Hsu HY, Chiu SL, Wen MH, Chen KY, Hua KF. Ligands of macrophage scavenger receptor induce cytokine expression via differential modulation of protein kinase signaling pathways. J Biol Chem 2001;276(31):28719-30.

[33] Hsu HY, Hajjar DP, Khan KM, Falcone DJ. Ligand binding to macrophage scavenger receptor-A induces urokinase-type plasminogen activator expression by a protein kinase-dependent signaling pathway. J Biol Chem 1998;273(2): $1240-6$.

[34] Senokuchi T, Matsumura T, Sakai M, et al. Extracellular signal-regulated kinase and p38 mitogen-activated protein kinase mediate macrophage proliferation induced by oxidized low-density lipoprotein. Atherosclerosis 2004; 176(2):233-45.

[35] Koh JS, Lieberthal W, Heydrick S, Levine JS. Lysophosphatidic acid is a major serum noncytokine survival factor for murine macrophages which acts via the phosphatidylinositol 3-kinase signaling pathway. J Clin Invest 1998;102(4):716-27.

[36] Korporaal SJ, Van Eck M, Adelmeijer J, et al. Platelet activation by oxidized low density lipoprotein is mediated by CD36 and scavenger receptor-A. Arterioscler Thromb Vasc Biol 2007;27(11):2476-83.

[37] Whitman SC, Daugherty A, Post SR. Regulation of acetylated low density lipoprotein uptake in macrophages by pertussis toxin-sensitive $G$ proteins. J Lipid Res 2000;41(5):807-13.

[38] Nakayama M, Kudoh T, Kaikita $K$, et al. Class A macrophage scavenger receptor gene expression levels in peripheral blood mononuclear cells specifically increase in patients with acute coronary syndrome. Atherosclerosis 2008;198(2):426-33.

[39] Tomokiyo R, Jinnouchi $\mathrm{K}$, Honda $\mathrm{M}$, et al. Production, characterization, and interspecies reactivities of monoclonal antibodies against human class A macrophage scavenger receptors. Atherosclerosis 2002;161(1):123-32.

[40] Teupser D, Stein O, Burkhardt R, Nebendahl K, Stein Y, Thiery J. Scavenger receptor activity is increased in macrophages from rabbits with low atherosclerotic response: studies in normocholesterolemic high and low atherosclerotic response rabbits. Arterioscler Thromb Vasc Biol 1999;19(5):1299-305.

[41] Jalkanen J, Leppanen P, Narvanen O, Greaves DR, Yla-Herttuala S. Adenovirusmediated gene transfer of a secreted decoy human macrophage scavenger receptor (SR-AI) in LDL receptor knock-out mice. Atherosclerosis 2003;169(1):95-103. 